Anticipating ubiquitous computing: logics to forecast technological futures

Sam Kinsley

Amory Building

College of Life and Environmental Sciences

University of Exeter

Exeter, EX4 4RJ

Email: s.kinsley@exeter.ac.uk

Words: 8,971 


\title{
Anticipating ubiquitous computing: logics to forecast technological futures
}

\begin{abstract}
Visions of the future predict spaces apparently teaming with ever more novel and pervasive technologies. Significant amongst such forecasts is the notion of 'ubiquitous computing' (ubicomp), understood as an affordance or capacity tied (in)to people, places and things. This article stages an encounter between the futurity of ubicomp and recent debates in geography around anticipation. So, first, the future orientation in ubicomp research and development (R\&D) is investigated as a mode of anticipation. 'Knowledges', and 'logics' of anticipation are subsequently, and second, discussed as the conceptual apparatus that constructs and perpetuates the 'proximate future' of ubicomp. This analysis connects recent discussion about 'anticipation' in social sciences research with the methods of ubicomp research, which fits with an emergent agenda around futurity in human geography. Third, the conceptual articulation of 'anticipatory logic' is applied to the analysis of empirical investigations of ubicomp R\&D to identify the specific logics of anticipation at play. This article accordingly examines the logics of anticipation that both support and destabilise the certainty with which the future is imagined within ubicomp. In conclusion, the multiple ways of anticipating a future world and the ways in which they discipline understandings of futurity are framed as a politics of anticipation.
\end{abstract}

Key words: futurity, anticipation, knowledge, logic, ubiquitous computing

\section{Introduction}

'The best way to predict the future is to invent it' — Alan Kay, Senior Engineer, Xerox PARC, 1971

'Sal glances out her windows: a grey day in silicon valley, 75 percent humidity and 40 percent chance of afternoon showers; meanwhile, it has been a quiet morning at the East Coast office. Usually the activity indicator shows at least one spontaneous urgent meeting by now...

Coming back to her office, Sal picks up a tab and "waves" it to her friend Joe in the design group, with whom she is sharing a virtual office for a few weeks. They have a joint assignment on her latest project. Virtual office sharing can take many forms--in this case the two have given each other access to their location detectors and to each other's screen contents and location. Sal chooses to keep miniature versions of all Joe's tabs and pads in view and 3-dimensionally correct in a little suite of tabs in the back corner of her desk. She can't see what anything says, but she feels more in touch with his work when noticing the displays change out of the corner of her eye, and she can easily enlarge anything if necessary.' (Weiser, 1991, p. 74)

In an influential Scientific American article Mark Weiser, then a Principal Scientist at Xerox

Palo Alto Research Centre (PARC), elucidated his vision of 'ubiquitous computing' 
through the fictional world of 'Sal'. As many have asserted (for example: Bell and Dourish, 2007; Galloway, 2004), Weiser's depiction of computer use 'beyond the desktop' and as a 'part of the woodwork' spawned the research arena of ubiquitous computing (or 'ubicomp'). It is, however, difficult to tie down exactly what is variously meant by the now widespread term 'ubicomp'. Many terms are taken as synonymous with Ubicomp, for example: 'ambient intelligence' (Information Society Technologies Advisory Group, 2003), 'everyware' (Greenfield, 2006) or 'pervasive computing' (Satyanarayanan, 2002). Yet, Weiser's vision of ubicomp as 'the computer for the $21^{\text {st }}$ century' still stands out, both in terms of its frequency of citation and the way in which it has inspired subsequent forecasts. The geographical significance of ubicomp is then twofold: first, the construction of new forms of technological spatial encounter, second, and the focus of this paper, the proposition of possible worlds. Bearing in mind ubicomp also describes a whole arena of computing research, in this paper I take ubicomp to broadly mean, and to quote Scott Carter (Research Scientist at FX PAL): "the application of computational tools to human activity, regardless of the shape and form of those tools"

The empirical basis of this paper is a set of interviews conducted during July and August 2008 in Silicon Valley, California, with a range of people involved in the research and development $(\mathrm{R} \& \mathrm{D})$ of ubicomp. Interviews were conducted with research industry experts and employees of industrial research laboratories of technology corporations, including HP Labs, Intel, Nokia, and Fuji Xerox ${ }^{2}$. The individuals approached for interviews work in the principal commercial research institutions for ubicomp R\&D, and are amongst the most accomplished practitioners of such research. The interviews addressed how the future is conceptualised in ubicomp $\mathrm{R} \& \mathrm{D}$ and the rationales for

\footnotetext{
${ }^{1}$ Taken from an interview conducted in Silicon Valley, California, in August 2008.

${ }^{2}$ The interviewees have been anonymised as Researchers A, B, C and D, with the exception of Bo Begole, of PARC.
} 
anticipation employed by those involved. This fieldwork explicitly opens up ubicomp to geographical enquiry as a relatively unexplored arena of geographical investigation.

Social scientists' investigations of ubicomp have been few but notable (see: Andrejevic, 2005; Crang and Graham, 2007; Dodge and Kitchin, 2007; Galloway, 2004). The vernacular is, however, familiar; ubicomp shares a vocabulary with popular, technologically concerned, future orientations. Ubicomp as an array of $\mathrm{R} \& \mathrm{D}$ activities is like many other branches of computer science, driven by problems emergent from past data and results but further, and more importantly, it is fixed on the abstract goal of achieving a perpetually near future inspired by the mythology arising from Weiser's (1991) research vision: 'Ubiquitous computing... encompasses a wide range of disparate technological areas brought together by a focus upon a vision' (Bell and Dourish, 2007, p. 358). The geographical significance of ubicomp R\&D is therefore twofold: first, the construction of new forms of technological spatial encounter, second, and the focus of this article, the narrative construction of technological futures founded in rationales of anticipation. This article examines the logic underlying ubicomp's implicit discourse of anticipation, which situates how future projection plays out in ubicomp R\&D. The analytical focus of this article is therefore the anticipatory action inherent to ubicomp $\mathrm{R} \& \mathrm{D}$ as a form of technical reasoning, which I argue underlies how material futures are imagined and built.

Anticipation, according to Mandel (2002, p. 246), is the future oriented 'ability for humans to conceptualise, to make abstractions, elaborate plans and imagine'. In this sense, anticipation, as a mode of thought, is the notion of making futures present, actually or virtually, somehow in advance. Following Adam and Groves' (2007, p. xiii) subtle distinctions between 'what will be', 'what might be', and what is desired, we can see that anticipation is a cognitive mechanism for engaging with futures. There is, however, a contradiction between a striving for stable futures and the occasionally 
unsettling difference of the making-present of the actual moment. Rather than affirm an ability to discern characteristics of future events, the success of which is highly improbable, I argue it is important to explore the means by which futures are characterised. Anticipation is employed here not as another all-consuming analytical category but as a signpost for a range of dispositions towards the future:

'not simply a given but a practical achievement emergent from... practices that create, know and govern possible, potential or preferred futures' (Anderson, 2007, p. 158).

It would be a mistake to offer some kind of typology to the vocabulary employed here but I would like to sketch some reasons for using the term 'anticipation'. Firstly, and simply, as a noun formed from a verb, anticipation has an inherently active sense. Secondly, and notably, there exists a literature on various ways of understanding futurity and particularly anticipation. A small but significant amount of work has been conducted in human geography explicitly on the ways in which futures are and have been figured and attempts have been made to engage with futures (for example: Adey, 2009; Anderson, 2006, 2007, 2010d; Budd and Adey, 2009; Evans, 2010; Kitchin and Kneale, 2001; Kraftl, 2007; Macnaghten, 2010; Pinder, 2001, 2005)³. Furthermore, complex interactions between past, present and future have been broadly addressed in human geography regarding diverse calls for, what Anderson (2010c, p. 4) terms, the 'anticipatory-utopian orientation to better futures' (for example: Braun, 2005; Harvey, 2000; kinpaisby, 2008; Wolch, 2007).

In cultural geography, specifically, an agenda for addressing geographies of anticipation has been opened up by Ben Anderson, regarding the development of nanotechnology (2007) and the practices of pre-emption and preparation of and for climate change, disease pandemic and, particularly, acts of terror (Anderson, 2010c,

\footnotetext{
${ }^{3}$ In September 2010 at the RGS-IBG Annual International Conference there was a three-part session concerning "Geography and the Future" that featured a wealth of geographical engagements with the concept and problem of the future.
} 
2010d). Anderson (2010c) suggests a novel vocabulary for understanding the discourse of anticipation within which he describes 'logics' and 'practices' of anticipation. In short, practices of anticipation are human cognitive and material engagements with the world that attempt to give content to futures. Further, logics of anticipation are the codified reasoning by which actions and statements to address particular futures are ordered in the present. I suggest that logics and practices of anticipation are always already in combination in the discourse of anticipation but get applied in specific instances, that apply to particular ways of thinking about anticipation, what we can call 'modes' of anticipation.

To explore how the proximate future of ubicomp remains as such and the spatialities that are thereby constructed, an encounter is staged between forecasts of ubicomp and recent debates in geography and cognate research around anticipation. In particular, discourses of anticipation are conceptualised here as the conjunction of knowledge and practice. More specifically, in this article, I argue that there are rationales, 'anticipatory logics', that underlie anticipatory action. Amongst the many methods for describing futures for ubicomp I argue there are two particular logics of anticipation, described as 'fabulation' and 'invention', which feature in the anticipatory action of ubicomp R\&D. These logics are explored in the second section of this paper as rationales that define repeatable means of instantiating the conditions and sense of anticipation inherent to ubicomp. I argue that we can understand a politics of anticipation as a way of marking and coding an array of practices rationalised through anticipatory logics. However, if 'politics' refers to 'a range of forms of action and practice' (Barry, 2001, p. 207), which become institutionalised and thus regulatory (Foucault, 1991a), then we must also understand the 'political' as distinct, following Agamben (1993). In this case, by political I mean a 'space of dissensus and contestation which is not reducible to politics' (Barry, 2001, p. 207). 
The logics for proactively thinking technological futurity come to an influential fruition in the imaginative description of ubicomp. This anticipation is exemplified by Weiser's (1991) story of 'Sal' (above) that helped launch ubicomp on the cusp of the 1980s and 1990s as a new arena of research. The characterisation of a technological future could be merely a marketing exercise, with obvious economic motivations, to make a claim on the future, as illustrated by Intel's current slogan: 'sponsors of tomorrow'4. However, the forecasts are not created by marketing staff, they are produced by researchers. The narratives that emerge do something more than tell stories: they propagate a mode of collectively thinking futurity. Ubicomp, as Bell and Dourish (2007, p. 142) point out, has been very successful on two counts. Firstly, as a research endeavour it has become not only a topic in its own right but also 'a central aspect of the research agenda for many other areas of computer science research' (ibid. p. 142). Second, as a broader technological vision, Weiser's (1991) model of 'a single person making use of tens or hundreds of embedded devices networked together[...] is a reality for many people' (Bell and Dourish, 2007, p. 142). The 'arrival' or making-present of this future, Bell and Dourish (ibid.) suggest, has been somehow missed, ostensibly because it is not as clean and ordered, instead it is 'messy'. It is on this point that our analysis parts ways, because I argue, following Massumi (2007a, 2007b), that anticipation remains as such and, indeed, propagates itself. I do not doubt that Bell and Dourish (2007) are correct in their suggestion that technologies that may be categorised as ubicomp exist, but that is a different proposition from the actualisation of a projection or vision of the future.

To investigate anticipatory action in and for the development of ubicomp, this paper proceeds in three steps. The future orientation in ubicomp $R \& D$ is, first,

\footnotetext{
${ }^{4}$ Retreived from the Intel Corporation website: http://www.intel.com/tomorrow/index.htm (accessed: 19/03/10).
} 
investigated in relation to foresight, which is described as a means of making futures present. 'Knowledges', and 'logics' of anticipation are subsequently, and second, discussed as the conceptual apparatus that construct and perpetuate the 'proximate future' (Bell and Dourish, 2007) of ubicomp. This analysis connects recent discussion about 'anticipation' in social sciences research with the methods of ubicomp research, which also fits with an emergent agenda around futurity in human geography. Third, the conceptual vocabulary of 'knowledge' and 'logic' of anticipation is applied to the analysis of empirical investigations of ubicomp R\&D to identify the rationales behind the anticipation at play. This article accordingly examines the logics of anticipation that both support and destabilise the certainty with which the future is imagined within ubicomp R\&D. In conclusion, the multiple ways of anticipating a future world and the ways in which they discipline understandings of futurity are framed as a politics of anticipation.

\section{Actively apprehending worlds}

Descriptive scenarios for particular futures play a significant role in ubicomp R\&D. Portrayals of possible worlds, following Weiser (1991), align people and projects with particular agendas. This imaginative forecasting begins from political economic imperatives, given a basis that 'the market' expects novelty and so R\&D must deliver it. However, I argue that forecasting stretches beyond such imperatives and this is where the particular interests of this article lie. The researchers that create these speculative accounts of futures do so knowing that they will not necessarily translate into commercially produced realities but that is not to say that such actions are not anticipatory. Prospective descriptions of particular types of future not only act as a means of proposing scenarios of technological experience, but also for expounding possible worlds in which such technologies are common place. These stories and scenarios produce influential spacings of people, places and things in relation to 
technology. A detailed imaginative description of a particular type of future, in the context of the investment of both emotive aspiration and pragmatic planning, attempts to concretise a 'tomorrow' today, to render it actionable.

However, given that a linear progress cannot be asserted, as Anderson (2010c, p. 14) observes: 'the future as surprise can only be rendered actionable by knowing a range of possible futures that may happen, including those that are improbable'. Stories about future technological experience are multiple in their telling, even if derived from the same source (such as Weiser, 1991). Nevertheless, tales of the future account for specific types of technologies used in particular ways. This representational specificity can, deliberately or otherwise, mask uncertainty: futures are apparently foreclosed, and doubts can be cast aside. Representation is thus key to the ways in which anticipatory action is exercised to encourage particular ways of thinking futures (see: Kinsley, 2010). We must therefore understand representation as performative; it is a form of practice that is enacted. Statements of foresight, like any discursive statement, following philosopher Brian Massumi's reading of Deleuze and Guattari (2004), are a 'performative use of language' (Massumi, 2002, p. xviii). Each story of the future accordingly transforms the state of affairs, bodies or material arrangements. This performative aspect of language is therefore 'a direct avenue for the passage of expression into content' (Massumi, 2002). At the same time, such anticipatory action must be based on a readiness to identify alternative possibilities, which may lead to radically different futures playing out (Anderson, 2010c). Those performative projections may subsequently become discursively aligned with a particular perspective on desirable attributes for a future.

If the aim of telling stories about particular futures is to facilitate decisionmaking, we must posit that there is a foreclosure of potential choices. Considered in terms of the practices of government, there are obvious parallels with Foucault's (1991a, 2007) understanding of governmental reason here. The ways in which research funding 
is channelled demonstrates, perhaps, the power of the 'programmatic' rationale of foresight ${ }^{5}$. Furthermore, the forecasts and imaginative representations that are supposed to translate between the space of anticipation and the time-space of potential futurity mask and warp according to the desires of those that create them. The experience of technological failure (Geels and Smit, 2000; Graham and Thrift, 2007) or cancellation before production (for example, the cancellation of the BAC TSR2 aircraft: Law, 2002, pp. 143-162) provides a significant demonstration of the differences between an anticipated, even intended, future and the actualised outcome. As interviewee Researcher $A$ of Nokia suggests:

"in the purely research arena we write so little about failures, we can't write a [conference] paper about a failed experiment ... you've got to show that its positive and, yes, people really want this, but the failures are the ones [the projects] that are so telling, and so important" (Researcher A, Nokia Research).

The agency of the production and proliferation of representations of the future in and through $\mathrm{R} \& \mathrm{D}$ is key to the institution, development and storytelling of ubicomp. This form of agency is performative; it is enacted in the utterance of statements.

Following the example of a recent Ubiquitous and Personal Computing article by Bell and Dourish (2007), I want to briefly unpack the narrative production of ubicomp. The anticipatory impetus for ubicomp was present from the outset, as Bell and Dourish (2007) assert, in the shape of Mark Weiser's 'foundational' article, entitled 'The Computer for the $21^{\text {st }}$ Century' (for a cultural studies perspective, see also: Galloway, 2004). Weiser's (1991) description of computing devices for (and in) a proximate future came out of an interdisciplinary experimental approach at the Palo Alto Research Centre (PARC). Weiser's (1991, 1998; 1999) vision, and subsequent experiments, positioned

\footnotetext{
${ }^{5}$ In ubicomp research, as with any other research community, the specifically directed channelling of funding resources is evident in the specification of research agenda, examples from the 'Ubicomp' 2007 conference being: ad-hoc connectivity of devices and systems, context-awareness (particularly location awareness) of devices, privacy and disclosure of information in systems, seamless, or 'seamful', integration of infrastructure.
} 
ubicomp technologies not in fanciful or outlandish scenarios but rather in apparently 'everyday' office or home life (Galloway, 2004, pp. 385-388). Those involved in this early ubicomp research place significant emphasis both in imagining futures by depiction through storytelling (cf. Gold, 2007, pp. 36-41) and constructing simulations of future computing environments (cf. Want et al., 1995; Weiser et al., 1999). This approach required significant investment and resources and certainly captured the imagination of scientists and engineers who took the research forward (see: Bell and Dourish, 2007, p. 134). In 2008, over 15 years on, Weiser's (1991) vision is still often presented as continuing such a 'looking forward', despite the arrival of the $21^{\text {st }}$ Century, to which Weiser (1991) referred, having come and gone. As Bell and Dourish point out:

'citations to Weiser's article are often phrased not so much as a "look backwards" but rather as a collective "look forwards"; that is, instead of saying "back in 1991, we thought that...", they say "Just as Weiser suggested in 1991, we are soon to enter a world where...” themselves' (Bell and Dourish, 2007, p. 135).

The centrality of a 'proximate future... just around the corner or over the horizon' (Bell and Dourish, 2007, p. 134) in Weiser's (1991) foundational articulation of ubiquitous computing, and the manner in which it continues to live in the writings of contemporary researchers ${ }^{6}$, perpetually places its achievements out of reach, while simultaneously eliding current technological practices. The framing of ubicomp as 'to come' allows researchers and technologists to 'absolve themselves of responsibilities for the present' (Bell and Dourish, 2007, p. 134) - the problems are described as 'implementation' issues that are or will be, essentially, someone else's problem. There are two forms of motivation for such forecasting that can be suggested here. First, there is a political economic motivation to either invent markets or capture market share. This is

\footnotetext{
${ }^{6}$ By Bell and Dourish's (2007, p. 134) reckoning, 51 of the 108 papers that made up the 'Ubicomp' conferences between 2001 and 2004 were specifically oriented towards a 'proximate (and inevitable) technological future' (ibid. p. 134). Indeed, Bell and Dourish (ibid.) suggest that of all of the papers published in the Ubicomp conference between 2001 and 2005, almost a quarter cite Weiser in reference to his vision.
} 
most frequently realised in the imperative to create novel ideas that can be patented, as Researcher B, of Fuji-Xerox Palo Alto Lab (FX PAL), suggests:

'Patents [are] pure novelty, and so... if you can show that you came up with something novel, even if its you know horribly destructive or whatever, um, its... its, you know, its patentable' (Researcher B, FX PAL).

The second motivation for anticipating particular types of future is a desire to 'change the world', an altruistic ambition that is largely cultural. Forecasting can accordingly be considered 'hopeful', following Anderson's (2006) reading of philosopher Ernst Bloch's conceptualisation of 'hope' as a lingering reference to a 'not-yet', a moment just out of reach. The 'world changing' rationale active in the futurity of ubicomp is, for many of the researchers interviewed, principally 'hopeful'. As another Nokia research scientist suggests:

'I think that... technology in general is a hopeful enterprise. And that we've seen dramatic improvements in the quality of everyday lives because of technology, but there's so clearly a huge gap to fill, a huge, you know, a long way to go... and ah, I think there are a lot of examples now of... how ah... you know, just the, the possession of the cell phone can economically and socially benefit ah, tremendously in third world countries, as an example' (Researcher C, Nokia Research Center).

The distance of an envisioned future from the present connotes a relative activity of that future - both in one's ability to affect its production and the ways in which that representation of a future can perform. As Michael (2000, p. 25) suggests, the relative distance of a represented future can give rise to different treatments and strategies:

'A future represented as far distant can be used to warrant slowness of action, but it can also draw the charge that it serves in a tactic of delay. A near future can warrant swift action, but it can also attract the accusation that it is no more than opportunism on the part of the actor who gains from some sort of 'scare' or other' (Michael, 2000, p. 25).

The relative proximity of the future frequently represented in ubicomp research, from the outset, has certainly prompted significant action - for example, it has resulted in the production of a lively and varied research community. Yet not only was the future of 
Weiser's story proximate, it remains so, as do the futures of subsequent and related accounts of ubicomp. The knowledge of what is anticipated remains anticipatory: 'A past anticipation is still an anticipation, and will remain having been an anticipation for all of time' (Massumi, 2007b). The implication of this remaining anticipation is that forecasts of the future have duration, they are realised or replaced, whereas the actuality of the present always contains the potential for surprise.

The running together of imaginative and experimental techniques of anticipation is clearly demonstrated in high profile public facing projects such as Microsoft Research's 'Being Human: Human-Computer Interaction in the year 2020' (Harper and Selin, 2007) and IBM's recent futuristic 'A Smarter Planet' agenda (IBM, 2009). IBM tie together existing research programmes (already translated into business projects) with less specific, more imaginative, aspirations. For example, the aspiration to produce, amongst others, smarter cities, governments and means:

'a world where digital intelligence can be embedded not just in individual things, but also across entire systems, impacting everything from traffic flows to electric power to the way our food is grown, processed and delivered... [C]onsider what's coming: sensors, cameras, cars, shipping containers, intelligent appliances, RFID tags by the hundreds of millions - all becoming interconnected. This will enable new, highly flexible ways of interacting with customers, employees, patients and citizens from any device, anywhere.' (IBM, 2009, p. 11)

In the Microsoft report ambitious anticipatory claims are made for growths of 'technodependency' (ibid. p. 40) and 'hyper-connectivity' (ibid. p. 43) in the 'shifting boundary between computers and humans' (ibid. p. 36). These forecasts are situated alongside experimental case studies, such as gesture-based computer interfaces (Harper and Selin, 2007, pp. 16-17), ‘smart fabrics’ utilising ‘Organic Light Emitting Diodes’ (ibid. p. 18) and the remote collaboration of multiple young musicians each with numerous (electronic) instruments and devices (ibid. pp. 47-48). None of which is very different from the world in which Weiser (1991) situated 'Sal'. 
To understand how anticipatory action in ubicomp functions we must understand the ways in which it is revealed in the practices of ubicomp R\&D. Furthermore, as I will argue in the next section, there are logics of anticipation by which those practices operate. Such anticipatory action is based in a historical situation of the presumption of particular forms of anticipatory knowledge being both possible and accessible. Indeed, foresight has an intellectual history as a form of anticipatory knowledge and practice that threads through theological and supernatural beliefs, and governmental techniques. Therefore in the next section I will deal with the constitution of anticipatory knowledge and develop an analytical vocabulary of 'knowledges' and 'logics' to enable a way of addressing the multifarious rendering of the future in technology development, and particularly ubicomp R\&D.

\section{Anticipatory knowledge and logics}

In his 2006 book Everyware: The dawning age of ubiquitous computing, Adam Greenfield extrapolates, with striking certainty, our future of living with ubiquitous computing from the apparently commonsense view of an increasingly technologised everyday life:

'Ever more pervasive, ever harder to perceive, computing has leapt off the desktop and insinuated itself into everyday life. Such ubiquitous information technology "everyware"-will appear in many different contexts and take a wide variety of forms, but it will affect almost every one of us, whether we're aware of it or not' (Greenfield, 2006, p. 9) .

This passage discloses the issue that this article seeks to address: a logical certainty with which the technological near future is frequently addressed. This certainty is achieved by

\footnotetext{
${ }^{7}$ It is worth noting that Greenfield plays with this certainty throughout his book and concludes by identifying the limits to addressing with any certainty the future of Ubicomp: 'These principles [he has suggested for design] are necessary but not sufficient: they constitute a beginning not an end' (Greenfield, 2006, p. 257).
} 
the adoption of various strategies for engaging with the future, which are figured here as 'anticipation'.

In relation to the practices of $\mathrm{R} \& \mathrm{D}$ in ubicomp, I argue that, as a discourse, anticipation is performed according to a range of logics, internal to that discourse, through which attempts to stabilise particular futures play out. In this section I will outline the 'knowledges' associated with anticipation, particularly related to governance, which can be read through recent discussions in geography, and cognate disciplines, about calculation (Elden, 2006, 2007) and fear (and pre-emption) (Massumi, 2005, 2007a, 2007b). From these debates, and building upon recent work by Ben Anderson (2010c), I suggest we can identify 'anticipatory logics', which function as repeatable means of instantiating the conditions and sense of anticipation, not only in governance but also in other forms of anticipatory action, such as R\&D. Furthermore, I will signal how these logics are partnered by and inform specific practices of anticipation.

There are many ways we describe a restless inclination towards the future. One ought to be careful not to elide the nuance in meaning realised in the many ways we use our vocabulary for future orientation. It would be a mistake to offer some kind of typology to this vocabulary but I would like to sketch some reasons for using the term 'anticipation' in particular. Within contemporary human geography Anderson has formulated an agenda for the study of 'anticipatory action' (2010c, p. 4) to question how 'the future' is being related to and how futures are 'known and rendered actionable' and 'to thereafter be acted upon'. Anderson (2010c, 2010d, 2010a, 2010b) addresses anticipatory action principally in relation to undesirable circumstances, such as the mitigation of terrorism, disease pandemic and natural disaster. However, these conceptual tools can also be brought to bear on aspirational forms of future oriented action, in this case ubicomp R\&D. There accordingly exists a nascent literature that can be rudimentarily classified through the themes of anticipatory 'knowledge' (Anderson, 
2007, 2010c, 2010a; Shields, 2008), anticipatory 'governance' (Anderson, 2007, 2010b; Barben et al., 2007) and anticipatory 'logic' (Anderson, 2005, 2010c; Kraftl, 2008). In this section I will discuss these related concepts and move on to develop an explanation of how the concepts of 'anticipatory logics' and 'anticipatory practices' can elucidate how futures are addressed in ubicomp research and development.

\subsection{Anticipatory knowledge}

The apparent apprehension and understanding of futures in particular contexts can be described as 'anticipatory knowledge'. Such 'knowledges' have origins in divination and clairvoyance (Anderson, 2007, p. 158), and have been historically linked to mechanisms of governance, for example - the 'haruspices' of ancient Rome advising the emperor of the most auspicious course of action (see: Thomson de Grummond, 2006). Whether or not we choose to believe the resulting predictions, clairvoyance continues today in various forms and remains practised as knowledge claims made about the future, for example through astrology. On the other hand, we might also describe scientific practices of climate and weather modelling as anticipatory knowledges, which have significant agency. As a result of the associated predictions, we feel we know what the weather will be tomorrow and that average global temperatures will continue to rise.

A need for anticipatory knowledge is derived from cultural and political economic imperatives, for example a certainty leads to 'peace of mind' or to a perceived market gain by claiming (imaginary/imaginative) territory. However, attitudes towards the future are not commonly held discretely. Instead, many of us splice together 'useful fictions' from scientific, religious, literary and philosophical means of addressing the future. These fictions are often inspired by (and occasionally inspire) future oriented scientific research. Shedroff and Noessel (2008) illustrate how Science Fiction can be a powerful influence on design, including the perceived potential utility or need. For 
example, the 'Xenotran Dynamic Sand Table' was commissioned and built for the U.S Army Topographic Engineers Unit inspired by the fictional portrayal of a dynamic threedimensional topographical mapping table in the film 'X-Men' (Shedroff and Noessel, 2008). As Kitchin and Neale (2001, p. 20) suggest Science Fiction literatures: 'inspire and articulate emerging popular geographical imaginations'. From such splicing of scientific forecast and imaginative elaboration are derived apparent 'knowledges' of future situations.

Various implementations of anticipatory knowledge are tied to forms of risk aversion, for example the risks of urban flooding, of financial loss or of global climate change. Risk, as an anticipatory knowledge, can thus be seen as calculable and collective, and (particularly in relation to insurance) in some senses constitutive of or derived from capital (Ewald, 1991, pp. 201-206). The intention of risk-related anticipatory knowledge is to identify and mitigate 'exceptional' circumstances that happen to us. Yet, whereas scientists may provide specific bounds of probability, a potential turn of events is often rendered, either by accident or design, as a certainty in the popular press (cf. Hollingshead, 2008; Jasny et al., 1999). Many forms of anticipation are tied to a sense of 'progress', which can imply a singular narrative of the passage of time, a time that happens to us. However, much of ubicomp operates within a different sense of anticipation, that of the production of possibilities. It is a difference evident between the experimental ethos of computer science pioneer Alan Kay's quote that opens this article, and the risk-averse concerns of Kay's management: "What was the future going to be like and how can [we] defend against it?" (Don Pendery, Vice-President of Xerox in 1971, cited by Markoff, 2005). Indeed, Weiser was upholding similar values to Kay in his perhaps more imaginative rendering of the future.

Plans and programmes are constructed on the basis of certain types of anticipatory knowledge, especially by governments, in the attempt to direct futures. The 
'system of knowledge-power' produces objectives that are the things (to be) controlled by being wanted for the desired future (Foucault, 2007, p. 42). Exercises in programming attempt to address the complexity inherent to notions of an unscripted future by masking that complexity, in favour of goals and targets that can be measured. Programmes, following Foucault (1991b, 2007), result in a governmental apparatus, which necessarily focus on that which may be controlled, and attempt to mask what lays outside of control. Whilst programmes and their resulting apparatuses of control can assert a conventional mode of anticipation they remain one of 'a set of diverse realities articulated onto each other' (Foucault, 1991b, p. 81), all producing a different sense of futurity:

'The difference between envisioned aims of a program and its actual effects does not refer to the purity of the program and the impurity of reality, but to different realities and heterogeneous strategies' (Lemke, 2002, p. 56).

Following Elden's (2007) further discussion of the programmatic nature of 'governmentaility', in Foucault's (2007) lecture-based explication, it is argued that one can understand modern modes of government as founded on a 'programmatic' logic or 'calculus'. Such calculative 'governmental reason' (2007, pp. 286-289) codifies, quantifies and thus accounts for the various elements of society not only in the present but also, and more pertinently, towards particular ends. The anticipatory nature of governmental reason makes the state the strategic objective of 'that form of calculation, and that form of intervention called politics... as [a] rational form of the art of government' (ibid. p. 287). Statistics was born as the technology of this anticipatory governance: 'a common instrument to both the balance of power and the police, because both are concerned with the forces and resources of states' (Elden, 2007, p. 573) ${ }^{8}$. However, statistics has

\footnotetext{
${ }^{8}$ Statistics as a programmatic calculus provided a basis for the disciplinary regimes Foucault (1991b, p. 80) highlights as 'calculated, reasoned prescriptions in terns of which institutions are meant to be reorganised, spaces arranged, behaviours regulated'. Noteworthy here is that the 'calculus' statistics comes etymologically from the German Statistik (Shaw and Miles, 1979) or
} 
been developed to become, for some, the instrument of articulating the fundamental uncertainty of a concrete world around us, the risks and probabilistic contingencies, that has frequently 'slipped through the meshes of the scientific net' (Whitehead, 1938, p. 25).

What we can see, then, is a move beyond the prescriptive calculus of $18^{\text {th }}$ century governmental modes of addressing the future, towards accepting the contingency inherent to any futurity. Perhaps nowhere has this been more applicable than in relation to nascent technology development. With the emergence of Genetically Modified Organisms (cf. Bingham, 2006, 2008) and nanotechnology (Anderson, 2007; Shields, 2008) there has been overt reference to the application and development of forms of 'anticipatory governance'. Whereas futures have long been addressed by governments through statistical calculation, 'anticipatory governance' in contemporary discourse explicitly embraces the inherent contingency of futurity. Indeed, in recent Science and Technology Studies literature, anticipatory governance, as it is discussed in relation to nanotechnology (Anderson, 2007; Barben et al., 2007; Selin, 2006; Shields, 2008), is figured as

'based on more than sound analytical capacities and relevant empirical knowledge: It also emerges out of a distributed collection of social and epistemological capacities... For, although action and outcomes are emergent qualities of human choice and behaviour, they rarely, if ever, proceed from certainty or prediction... Anticipation implies an awareness of the co-production of sociotechnical knowledge and the importance of richly imagining sociotechnical alternatives that might inspire its use' (Barben et al., 2007, pp. 991 992).

There has been, however, an alternative model of anticipatory governance that plays on precisely that disposition towards risk as a means of coercion. Fear has long been an effective means to subdue a particular group. In the case of recent anti-terror measures, governments have employed the possibility of unspecified threat, in this way

'state-istics' (Crampton and Elden, 2006, p. 682) and underwrote the technologies of $17^{\text {th }}$ and $18^{\text {th }}$ century governance, which for Foucault (2007) constituted 'the essential content of the sovereign's knowledge' (ibid. p. 274). 
'knowledge' is destabilised - for 'a threat is unknowable' (Massumi, 2005, p. 35). The basis for an anticipatory governance founded on fear is indeterminacy. If the origin, target and timing, perhaps even the likelihood, of a threat is unspecified, its apparent imminence can be maintained and mobilised to justify action. A 'future cause' for response, a threat, is thus identified and a (potential) future is granted an effect in the present:

'Fear is the palpable action in the present of a threatening future cause... You leap into action on a level with the potential that frightens you... You turn the objectively indeterminate cause into an actual effect so you can actually deal with it in some way' (Massumi, 2007a, p. \$18 original emphasis).

\subsection{Anticipatory logic}

A form of logic, whether deliberative or emergent, evidently underlies both the divination of 'anticipatory knowledge' and the programmatic calculus of 'anticipatory governance'. Massumi (2007a, 2007b) describes the radical form of anticipatory governance enacted, by the Bush administration, as a co-productive 'logic of preemption' (Massumi, 2007a, p. \$13). 'Pre-emption’ because the logic dictates that one acts before a threat has even emerged (ibid. p. \$13) and 'co-productive' because, as Massumi (ibid) suggests, '[t]he most effective way to fight an unspecified threat is to actively contribute to producing it' (p. \$16 original emphasis). Massumi (2007a, 2007b) addresses pre-emption as an 'operative logic' of future orientated fear. Populations might be controlled by the disquietude of a looming possible threat, a threat that self-perpetuates:

'An operative logic is a productive process that inhabits a shared environment, or field of exteriority, with other processes and logics. It figures in that field as a formative movement: a tendency toward the iterative production of its own variety of constituted fact' (Massumi, 2007b, p. 17)

If logic is the codified or structured reasoning through principles of valid inference (following the definition found in Oxford English Dictionary 1989) then 'operative logics', following Massumi (2007b), are those that include in that structure of 
reasoning the means for extending themselves. Modes of anticipation, I think, are perpetuated by operative logics. Evidence for this 'operative' function can be found in Massumi's (2007a) example of pre-emption, the iterative production of governmental measures and targets, and also, perhaps, in the self-perpetuating nature of forecasts and projections in technology research (to which we will return later). Furthermore, I suggest that the instantiation of anticipation in particular is performed through 'anticipatory logics'. What might accordingly be identified are frameworks through which 'acceptable' or 'credible' means of addressing the future are qualified. The programmatic application of statistical techniques and the propagation of threat to prompt recourse for action demonstrate the application of the discourse of anticipation as logical constructs for governance.

This mobilisation of anticipatory (and operative) logic is not, however, necessarily peculiar to anticipatory governance. Anticipatory logics are also evident in the qualification of 'credible' means of asserting knowledge or making predictions about futures. In laying out starting points for thinking through how anticipatory action happens, Anderson (2010d) identifies logics of anticipation as intimately tied to practices of anticipation. An anticipatory logic, for Anderson (2010d, p. 6), is 'a programmatic way of formalising, justifying, and deploying action [related to the future] in the here and now'. Similarly, Winner (2004, p. 37 original emphasis) describes the rationale of anticipating futures for technologies as asserting action: 'the operative verb tense in projections is will. These things will happen'. Yet, as the variety of mission statements for technology research programmes attest, there is a cacophony of competing futures that, apparently, 'will' happen.

In particular, the figuring and discussion of futures in ubicomp $R \& D$, considered as the mode of anticipation 'foresight', relies upon particular anticipatory practices that are rationalised by corresponding logics of anticipation. This mechanism, or 'mode of 
anticipation', for addressing futures and rendering them apparently actionable lies at the heart of how the future is figured in the spatial imagination of ubicomp. As one (former) HP Labs researcher suggested:

" $\mathrm{A}[\mathrm{t}]$ an industrial research lab your job is to think about and develop technologies that could lead to interesting opportunities some time in the future, so, almost by definition, you're always working in a future tense" (Researcher D).

In relation to the multiple nature of (plural) representations of possible futures that are produced in $\mathrm{R} \& \mathrm{D}$, it is perhaps something like a future 'subjective' tense, insofar as the premise for the anticipatory forecast is 'given the perfect world for our technology, this is what should happen', which might be somewhat removed from what is otherwise anticipated for the future.

To probe the inter-related logics and practices of anticipation that constitute the staging of proximate futures for ubicomp I turn to an exploration of how practitioners describe the future oriented processes in which they engage. These examples both demonstrate and distil the differences of the mode of foresight as played out through ubicomp, signalled in the argument above. If, following oft-quoted Science Fiction author William Gibson, there is a belief amongst those involved in ubicomp that 'the future is already here; it's just not very evenly distributed' (Gibson, 1999; cf. Bell and Dourish, 2007, p. 141; Harper and Selin, 2007, p. 83), we must surely ask if this collective sense of futurity and its various instantiations is self-perpetuating. In the next section of the article I explore the logics of anticipation through which claims on the future are rationalised.

\section{Anticipatory logics of ubicomp}

Within the discourse of anticipation for ubicomp R\&D, I argue that particular logics that regulate how practices of anticipation are enacted. Following the description of the three practices of imagining, enacting and specifying futures, I will now address 
the logics that I believe facilitate their function. I have already suggested that anticipatory logics are coherent and repeatable means by which action in the present on the basis of the future is coded and conditions for a sense of anticipation are instantiated. An anticipatory logic is thus the conditioning mechanism by which statements about 'the future' are conditioned and the presence of specific 'futures' is apparently rendered. I focus here on two, which I have identified as: fabulation and invention. Some logics of anticipation may be co-opted into or originate from idealist or ideological scripts, for example 'pre-emption' in relation to the war on terror (see: Anderson, 2010c; Massumi, 2007a). In contrast, the logics by which those who practice $R \& D$ attempt to gain foresight carry less rhetorical baggage. They are certainly political, however, insofar as the logics of fabulation and invention rationalise claims over particular types of future. The goal of these logics of anticipation, then, is to produce and develop the potential for novel forms of technological encounter. In the remaining part of this section I will outline the properties of the two anticipatory logics.

First, I have used the word 'fabulation' to describe a rationale for imaginatively creating attributes and stories for particular types of future. We might, just as easily, talk about a rationale of 'story telling' or 'imaginative representation', however, 'fabulation' offers a more specific definition. Following the Oxford English Dictionary we can understand 'fabulation' as 'to talk or narrate in fables' (1989, additional emphasis), which in turn are fictitious narratives or statements, or short stories, 'devised to convey some useful lesson' (ibid). My use of 'fabulation' here is to signify the logic for story telling a means of garnering foresight of possible, probable or preferred futures. I argue this is a prevalent logic within practices of anticipation in computing $R \& D$ and it is an important part of how the broad community of ubicomp researchers understand their own work. As Bell and Dourish (2007) suggest, reflecting on the influence of Weiser's originating research 'vision': 
'the same concern with technological futures continues to feature in the ways in which ubicomp research agendas are framed and in which technological advances are motivated an measured' (Bell and Dourish, 2007, p. 133).

For example, in the opening to Välkkynen et al.'s chapter describing the advent of 'physical browsing' using mobile devices a future scenario is offered as the most efficient means of introducing the suggested 'interaction paradigm':

'Joe has just arrived on a bus stop on his way home. He touches the bus stop sign with his mobile phone and the phone loads and displays him a web page, which tells him the expected waiting times for the next buses so he can best decide which one to use and how long he must wait for it. While he is waiting for the next bus, he notices a poster advertising an interesting movie. Joe points his mobile phone at a link in the poster and his mobile phone displays the web page of the movie. He decides to go see it in the premiere and clicks another link on the poster, leading him to the ticket reservation service of a local movie theatre' (Välkkynen et al., 2006, p. 61).

There are thus elements of fabulation in many practices of anticipation for ubicomp, for fabulation is at the heart of the production of 'useful' fictions. These fictions are the stories told to introduce a set of ideas, as demonstrated, as well as the 'fictive frames' (Dourish and Bell, 2008) that facilitate the 'as if user interaction in lightweight prototypes'.

Consider one example of the deployment of fabulation; a set of 'visions', produced by PARC, that describe a future of 'harmonious interaction' with and through technology that would allow people to

'communicate, learn, share, create and access information, as well as interact with objects in the physical environment, spontaneously and effortlessly as they go about their everyday lives' (Begole and Masuoka, 2008, p. 635).

The vision of the future represented here draws heavily on an analogous comparison with characterisations of 'Eden' as a perfect environment in which to live. As we learn from the principal author of this 'vision', it is not one but, in fact, several imaginative representations of a possible future that fit together:

'the harmonious interaction is really just an umbrella vision really and the three sub-dimensions in that are more what we pay attention to on a day to day basis: 
pro-activity, natural interaction and ubiquity. And within those we also have subprojects within it, so like the natural interaction, there's a piece of that which has to do with making it easy to use your mobile device and there's a piece of that which has to do with using sensors to detect your needs and then that feeds into the pro-activity too, you know, having detected something then satisfying that. And that's more at the level we operate, when we're planning things out, ok so, we've said - here's this umbrella objective, here's the three ways we're going to attack that problem, because the problem is not concrete enough to solve directly, its just this, as you say, you know, quite amorphous goal, so here's our three strategies, here's our three bets, on how it'll be accomplished within whatever, and that's what we focus on, day to day' (Bo Begole, PARC).

Fabulation is the logic that legitimises storytelling as a valid research practice, it is the set of rules that enable 'fictional' statements about the future, within the discourse of anticipation.

Second, 'invention' is the most well known, and perhaps the greatest catchall, of logics. However, I am applying the term in a specific sense here, following James Utterback's (1994) distinction between invention, as 'ideas and concepts for new products or processes' and innovation as the 'reduction of an idea to the first use or sale' (Utterback, 1994, p. 193). Thus, invention is significantly different in rationale from innovation. Invention, as David Nye (2006) suggests, does not necessarily stem from the 'eureka' moment, neither does it provide a certain route to fame and fortune, instead it is the rationale of curiosity. Specifically, invention is the logic by which novelty is recognised and extrapolated into a potential future, as Barry suggests:

'what is inventive is not the novelty of artefacts and devices in themselves, but the novelty of the arrangements with other objects and activities within which artefacts and instruments... might be situated in the future' (Barry, 2001, pp. 211-212).

Let us briefly focus on one particular researcher's experience of using 'paper prototyping' techniques within his R\&D practice to differentiate this understanding of 'invention'. 'Lightweight' or 'paper' prototypes can be used to rapidly create an experience of using a technology 'as if' it were a functional device. According to Snyder 'paper prototyping' is 'a widely used method for designing, testing and refining user 
interfaces' (2003, p. 3). Proponents of paper prototyping suggest it offers a fast means of providing a reasonably 'deep' experience of a potential technology with the ability to rapidly iterate through versions of the design (see: Beyer and Holtzblatt, 1999; Snyder, 2003). However, in light of the experiences of Researcher B, it is evident that the potential futures invented are not always desired:

'I did some experiments using lightweight prototypes of umm... peripheral displays and sensing systems and I found it... um... I found that... the direction I went in once I had actually started getting some interactive technology into peoples' hands ended up being so drastically different from any of the scenarios that I built beforehand that it seemed not as important to ensure that scenarios are all that great, you need to have some general direction of course and some idea, but you need to not be married to it and not take it too seriously... because you really don't know what it is you've actually done until you've put it in play.' (Researcher B, FXPAL)

The potential for alternative futures that have not been previously anticipated emerges from the participation of the user. This can, of course be productive of different forms of anticipatory experience and it raises interesting questions about the disciplinary action of this form of anticipatory logic. For example, such techniques may question the stability of the set of statements that govern what is sayable about the future but also demonstrates the means by which space is made for new statements to be made or, in this context, enacted. Interestingly, an alternative version of this technique was also discussed as an evolution of the practice of enacting futures within the R\&D practices of the informant:

'Sketches are exploratory, sketches are... you're just trying to get a handle on an idea, you have no real comparison... you would get, ah, you know rely more on, say, focus groups, but again probably with people who were, have a lot of experience, not just some random user communities. ... in many cases, you would, ah, just create a variety of different designs and then have people evaluate them and... you'd always use people who have lots of experience doing this... not using people who're developing it but people... from outside, just like you would with a design critique, and have them come in and evaluate these different platforms' (Researcher B, FXPAL). 
Ideas are struck upon and developed using techniques, such as those explored above, to formulate possible worlds. To return to the example of the experimental ethos of computer science pioneer Alan Kay 'the best way to predict the future is to invent it' (see: Markoff, 2005). Following philosopher Isabelle Stengers, we might understand invention as a 'passion of creating new possiblity' (Stengers and Zournazi, 2002, p. 248). Invention is accordingly a motiviating rationale for activities such as prototyping and in the specification of 'solution spaces' to map out possible technologies.

Fabulation and invention are both means of guiding action that functions through anticipation to make futures apparently present and thus actionable. The anticipatory logics of fabulation and invention both attempt to elicit a sense of foresight. In this section I have demonstrated how the 'presence of the future' is constructed and actions are made upon that assumption through particular forms of anticipatory logic. Through logics of 'fabulation' and 'invention' of futures, possible, probable and preferred worlds of ubicomp are produced within ubicomp R\&D. I have discussed how ubicomp R\&D employs these logics of anticipation to produce and develop the potential for novel forms of technological encounter. In the final section of this article I signal how these logics rationalise a discourse of futurity, which raises to the fore a politics of anticipation.

\section{Conclusions}

I have argued that the knowledge of what is anticipated in technology research and development remains anticipatory and thus by looking at the rationales, or anticipatory logics, that are used in their production, we can examine the ways in which such futurity is produced. A key tenet of the anticipation that plays out in ubicomp is, I argue, an 'operative logic' (Massumi, 2007a) of looking forward. Anticipation, and particularly the fabulation or invention of a future, is an iterative process. Anticipatory 
action has a duration, as discussed above, but it is motivated by 'operative logics', such as fabulation and invention, because their ethos inherently perpetuates further anticipation. I want to conclude, therefore, with some remarks about a politics of anticipation.

The activities of negotiating how the desired (or feared) attributes of a technological future are addressed, and what they mean, encode and condition how we can relate to such futures more broadly. I have already suggested that a politics of anticipation is the coding of practices rationalised through anticipatory logics. In broad terms, the means of organising or coding futurity are the accepted forms of terminology and techniques used to make particular futures present. I have identified the rationales by which the techniques of storytelling and 'as if prototyping (devices and systems that are not yet realised) operate as logics of anticipation, specifically: 'fabulation' and 'invention'.

An integral part of the performance of futurity in ubicomp R\&D is the implicit conditions such forms of anticipation lay down. While such conditions of anticipation may not be programmatic, in the sense of Foucault's (2007) 'governmental reason', these conditions assert bounds to a discourse of anticipation. These conditions identify the groupings of statements and practices that determine the ways that it is acceptable to address futures of ubicomp. This is not the assertion of disciplinary authority, rather the politics played out in the codings and conditions of anticipation is the ongoing negotiation of control over what it is possible to say about the future(s) of ubicomp.

Telling stories about futures of ubicomp can be politically productive because the stories may inspire and provoke debate about the direction of research and possible uses of what might otherwise be considered 'value neutral' technologies. There are multiple ways in which anticipatory logics are employed and, by which, accounts of futures of ubicomp are constructed. This leads to attempts to make present a variety of alternative, sometimes, contested, futures. In this sense it might be suggested that technological 
R\&D has an innate political value. Interestingly, similar concerns have spawned an associated literature for 'value-sensitive design' (Friedman, 1997). While imaginative forecasts such as Weiser's 'Computer for the 21st Century' have a regulatory effect on the ways in which practices of anticipation play out, the discourse of anticipation allows for more subtlety. The statements through which we can describe, and attempt to make present, particular types of future contain variety that allows for the potential of difference in the repetition of 'operatively' perpetuated anticipation.

Inspired and troubled by the various ways in which particular types of future for ubicomp are, and have been, forecast (as well as by work such as: Anderson, 2007; Bell and Dourish, 2007; Bingham, 2008; Galloway, 2004), in this article I have described a politics of anticipation. It is not difficult to see how the techniques of anticipation can become programmatic, when arranged on 'macro' levels by large corporations for example, but, I think, there is always space for nuance and dissent that leads to a departure from such a regime. If the 'political' is the space for dissent and opposition then the sense in which our collective futurity is seemingly enrolled into normative conventions of an ongoing technological 'progress' is perhaps disciplinary or 'antipolitical'. Through the imposition of conventional descriptive 'meta' narratives alternative futures can be somewhat 'coded' out of the ways 'the future' is made present. However, it is the possibility of difference inherent in the fact that anticipatory logics (and the practices they rationalise) operate in the present, upon never actualised 'proximate futures', that leaves intact the open potential of 'future presents'. This is precisely why, I think, Weiser's (1991) vision for ubicomp has endured. By looking at the logics by which anticipatory action is performed it is possible to examine the ways in which our knowledge and practices of technological anticipation construct our collective sense of futurity. 


\section{Bibliography}

1989 Oxford English Dictionary. Second Edition, Oxford University Press, Oxford.

Adam, Barbara, Groves, Chris, 2007 Future Matters: Action, Knowledge, Ethics. Brill, Leiden, NL and Boston, MA.

Adey, Peter, 2009, "Facing airport security: affect, biopolitcs and the preemptive securitization of the mobile body" Environment and Planning D: Society \& Space 27 (2), pp. 274-295.

Agamben, Giorgio, 1993 The Coming Community. University of Minnesota Press, Minneapolis, MN.

Anderson, Ben, 2005, "Practices of judgement and domestic geographies of affect" Social \& Cultural Geography 6 (5), pp. 645-659.

Anderson, Ben, 2006, "'Transcending without transcendence": Utopianism and an ethos of hope" Antipode 38 (4), pp. 691-710.

Anderson, Ben, 2007, "Hope for nanotechnology: anticipatory knowledge and the governance of affect" Area 39 (2), pp. 156-165.

Anderson, Ben, 2010a, "Morale and the Affective Geographies of the 'War on Terror'" Cultural Geographies 17 (2), pp. 219-236.

Anderson, Ben, 2010b, "Population and affective perception: biopolitics and the anticipatory action in US counterinsurgency doctrine" Antipode forthcoming.

Anderson, Ben, 2010c, "Preemption, Precaution, Preparedness: Anticipatory Action and Future Geographies" Progress in Human Geography forthcoming.

Anderson, Ben, 2010d, "Security and the future: Anticipating the event of terror" Geoforum 41 (2), pp. 227-235.

Andrejevic, Mark, 2005, "Nothing comes between me and my CPU: smart clothes and "ubiquitous" computing" Theory, Culture \& Society 22 (3), pp. 101119.

Barben, Daneil, Fisher, Erik, Selin, Cynthia, Guston, David H, 2007, "Anticipatory Governance of Nanotechnology: Foresight, Engagement, and Integration". In: Hackett, E. J., Amsterdamska, O., Lynch, M., Wajcman, J. (Eds.) The Handbook of Science and Technology Studies. MIT Press, Cambridge, MA, pp. 979-1000.

Barry, Andrew, 2001 Political Machines: Governing a technological society. Athlone, London. 
Begole, Bo, Masuoka, Ryusuke, 2008, "Search for Eden: Historic perspective and current trends toward the ubiquitous computing vision of effortless living" Information Processing Society of Japan Magazine 49 (6), pp. 635-640.

Bell, Genevieve, Dourish, Paul, 2007, "Yesterday's Tomorrows: Notes on ubiquitous computing's dominant vision" Personal and Ubiquitous Computing 11 (2), pp. 133-143.

Beyer, Hugh, Holtzblatt, Karen, 1999, "Contextual design" Interactions 6 (1), pp. 32-42, 291229.

Bingham, Nick, 2006, "Bees, butterflies, and bacteria: Biotechnology and the politics of nonhuman friendship" Environment and Planning A 38 (3), pp. 483498.

Bingham, Nick, 2008, "Slowing things down: Lessons from the GM controversy" Geoforum 39 (1), pp. 111-122.

Braun, Bruce, 2005, "Writing Geographies of Hope" Antipode 37 (4), pp. 834841.

Budd, Lucy, Adey, Peter, 2009, "The software-simulated airworld: anticipatory code and affective aeromobilities" Environment and Planning A 41 (6), pp. 13661385.

Crampton, Jeremy W., Elden, Stuart, 2006, "Space, politics, calculation: an introduction" Social \& Cultural Geography 7 (5), pp. 681-685.

Crang, Michael, Graham, Stephen, 2007, "Sentient Cities: Ambient intelligence and the politics of urban space" Information, Communication and Society 10 (6), pp. 789-817.

Deleuze, Gilles, Guattari, Félix, 2004 Anti-Oedipus. trans. Hurley, R., Seem, M., Lane, H. R., Continuum, London.

Dodge, Martin, Kitchin, Rob, 2007, "'Outlines of a world coming into existence": pervasive computing and an ethics of forgetting" environment and Planning B: Planning and Design 34 (3), pp. 431-445.

Dourish, Paul, Bell, Genevieve, 2008, "'Resistence is Futile': Reading Science Fiction alongside ubiquitous computing" Personal and Ubiquitous Computing, forthcoming.

Elden, Stuart, 2006 Speaking Against Number: Heidegger, language and the politics of calculation Edinburgh University Press, Edinburgh. 
Elden, Stuart, 2007, "Governmentality, calculation, territory" Environment and Planning D: Society and Space 25 (3), pp. 562-580.

Evans, Bethan, 2010, "Anticipating fatness: childhood, affect and the preemptive 'war on obesity' " Transactions of the Institute of British Geographers 35 (1), pp. 21-38.

Ewald, François, 1991, "Insurance and Risk". In: Burchell, G., Gordon, C., Miller, P. (Eds.) The Foucault Effect: Studies in Governmentality. University of Chicago Press, Chicago, IL, pp. 197-210.

Foucault, Michel, 1991a, "Governmentality". In: Burchell, G., Gordon, C., Miller, P. (Eds.) The Foucault Effect: Studies in Governmentality. University of Chicago Press, Chicago, IL, pp. 87-104.

Foucault, Michel, 1991b, "Questions of Method". In: Burchell, G., Gordon, C., Miller, P. (Eds.) The Foucault Effect: Studies in Governmentality. University of Chicago Press, Chicago, IL, pp. 73-86.

Foucault, Michel, 2007 Security, Territory, Population: Lectures at the Collège de France 1977-78. trans. Burchell, G., Palgrave MacMillan, Basingstoke, UK \& New York, NY.

Friedman, Batya (Ed.), 1997 Human Values and the design of computer technology. CSLI Publications and Cambridge University Press, Stanford, CA and Cambridge.

Galloway, Anne, 2004, "Intimations of Everyday Life: Ubiquitous computing and the city" Cultural Studies 18 (2/3), pp. 384-408.

Geels, Frank W., Smit, Wim A., 2000, "Lessons from failed technology futures: Potholes in the road to the future". In: Brown, N., Rappert, B., Webster, A. (Eds.) Contested Futures: A sociology of prospective techno-science. Ashgate, Aldershot, UK, pp. 129-156.

Gibson, William, 1999, "Interview on National Public Radio's "Talk of the Nation", 30 November 1999",

Gold, Rich, 2007 The Plenitude: Creativity, innovation and making stuff. MIT Press, Cambridge, MA.

Graham, Stephen, Thrift, Nigel, 2007, "Out of order - Understanding repair and maintenance" Theory Culture \& Society 24 (3), pp. 1-25.

Greenfield, Adam, 2006 Everyware: The dawning age of ubiquitous computing. New Riders, Berkeley, CA. 
Harper, Richard, Selin, Abigail, 2007, "Being Human: Human-Computer Interaction in the year 2020", Microsoft Research, Cambridge.

Harvey, David, 2000 Spaces of Hope. Edinburgh University Press, Edinburgh.

Hollingshead, lain, 2008, "Science friction" The Guardian: Media, 28/04/2008, page 3.

IBM, 2009, "Conversations for a Smarter Planet" accessed online at http://www.ibm.com/smarterplanet/global/files/us_en_us_overview_COM03 003USEN.PDF.

Information Society Technologies Advisory Group, 2003, "Ambient Intelligence: from vision to reality", European Commission, Brussels, Belgium.

Jasny, Barbara, Hanson, R. Brooks, Bloom, Floyd E., 1999, "A Media Uncertainty Principle" Science, page 1453.

kinpaisby, mrs, 2008, "Taking stock of participatory geographies: envisioning the communiversity" Transactions of the Institute of British Geographers 33 (3), pp. 292-299.

Kinsley, Samuel, 2010, "Representing 'things to come': feeling the visions of future technologies" Environment and Planning A 42 (11), pp. 2771-2790.

Kitchin, Rob, Kneale, James, 2001, "Science fiction or future fact? Exploring imaginative geographies of the new millennium" Progress in Human Geography 25 (1), pp. 19-35.

Kraftl, Peter, 2007, "Utopia, performativity, and the unhomely" Environment and Planning D: Society \& Space 25 (1), pp. 125-143.

Kraftl, Peter, 2008, "Young people, hope, and childhood-hope" Space and Culture 11 (2), pp. 81-92.

Law, John, 2002 Aircraft Stories: Decentering the Object in Technoscience. Duke University Press, Durham, NC.

Lemke, Thomas, 2002, "Foucault, Governmentality, and Critique" Rethinking Marxism 14 (3), pp. 49-64.

Macnaghten, Phil, 2010, "Researching technoscientific concerns in the making: narrative structures, public responses, and emerging nanotechnologies" Environment and Planning A 42 (1), pp. 23-37.

Mandel, Ernst, 2002, "Anticipation and Hope as Categories of Historical Materialism " Historical Materialism 10 (4), pp. 245-259. 
Markoff, John, 2005 What the Dormouse Saw: How the Sixties counter-culture shaped the Personal Computer industry. Penguin, London.

Massumi, Brian, 2002, "Introduction: Like a thought". In: Massumi, B. (Ed.) A shock to thought: Expression after Deleuze and Guattari. Routledge, London, pp. $x i i i-X x x V$.

Massumi, Brian, 2005, "Fear (The spectrum said)" Positions-East Asia Cultures Critique 13 (1), pp. 31-48.

Massumi, Brian, 2007a, "Potential Politics and the Primacy of Preemption" Theory and Event 10 (2).

Massumi, Brian, 2007b, "The Future Birth of the Affective Fact: The political ontology of threat", Society for Literature, Science and the Arts Conference 2007,

Michael, Mike, 2000, "Futures of the Present: From performativity to prehension". In: Brown, N., Rappert, B., Webster, A. (Eds.) Contested Futures: A sociology of prospective techno-science. Ashgate, Aldershot, UK, pp. 21-39.

Nye, David E., 2006 Technology matters : questions to live with. MIT, Cambridge, Mass. ; London.

Pinder, David, 2001, "In defence of utopian urbanism: Imagining cities after the "end of utopia"" Geografiska Annaler Series B: Human Geography 84 (3-4), pp. 229-241.

Pinder, David, 2005 Visions of the city: Utopianism, power and politics in twentieth century urbanism Edinburgh University Press, Edinburgh.

Satyanarayanan, Mahadev, 2002, "A Catalyst for Mobile and Ubiquitous Computing" IEEE Pervasive Computing 1 (1), pp. 2-5.

Selin, C, 2006, "Time matters: temporal harmony and dissonance in nanotechnology networks" Time \& Society 15 pp. 121-139.

Shaw, M, Miles, I, 1979, "The social roots of statistical knowledge". In: Irvine, J., Miles, I., Evans, J. (Eds.) Demystifying Social Statistics. Pluto Press, London,

Shedroff, N, Noessel, C, 2008, "Make It So: What Interaction Designers can Learn from Science Fiction", in SXSW Conference, Austin, Texas,

Shields, Rob, 2008, "Hope and Fear in Biotechnology: The Space-Times of Regulatory Affect" Space and Culture 11 (2), pp. 125-141.

Snyder, Carolyn, 2003 Paper Prototyping: The fast and easy way to design and refine user interfaces. Morgan Kaufmann, San Francisco, CA. 
Stengers, Isabelle, Zournazi, Mary, 2002, "A 'cosmo-politics' - risk, hope, change". In: Zournazi, M. (Ed.) Hope: new philosophies for change. Pluto Press, Sydney, pp. 244-273.

Thomson de Grummond, Nancy, 2006, "Prophets and Priests". In: Thomson de Grummond, N., Simon, E. (Eds.) The Religion of the Etruscans. University of Texas Press, Austin, TX, pp. 27-44.

Utterback, James, 1994 Mastering the dynamics of innovaion. Harvard Business School, Cambridge, MA.

Välkkynen, Pasi, Pohjanheimo, Lauri, Ailisto, Heikki, 2006, "Physical Browsing". In: Vasilakos, A., Pedrycz, W. (Eds.) Ambient Intelligence, Wireless Networking, and Ubiquitous Computing. Artech House, Boston, MA and London, pp. 61-81.

Want, R., Schilit, B. N., Adams, N. I., Gold, R., Petersen, K., Goldberg, D., Ellis, J. R., Weiser, M., 1995, "An overview of the PARCTAB ubiquitous computing experiment" leee Personal Communications 2 (6), pp. 28-43.

Weiser, M., 1991, "The Computer for the 21st-Century" Scientific American 265 (3), pp. 66-75.

Weiser, M., 1998, "The future of ubiquitous computing on campus" Communications of the Acm 41 (1), pp. 41-42.

Weiser, M., Gold, R., Brown, J. S., 1999, "The origins of ubiquitous computing research at PARC in the late 1980s" IBM Systems Journal 38 (4), pp. 693-696.

Whitehead, Alfred North, 1938 Modes of Thought. Free Press, New York, NY.

Winner, Langdon, 2004, "Sow's Ears from Silk Purses: The strange alchemy of technological visionaries". In: Sturken, M., Thomas, D., Ball-Rokeach, S. J. (Eds.) Technological Visions: The hopes and fears that shape new technologies. Temple University Press, Philadelphia, NJ, pp. 34-47.

Wolch, Jennifer, 2007, "Green Urban Worlds" Annals of the Association of American Geographers 97 (2), pp. 373-384. 